\title{
Maternal factors regulating preterm infants' responses to pain and stress while in maternal kangaroo care ${ }^{1}$
}

\author{
Thaíla Corrêa Castral² \\ Fay Fathalee Warnock ${ }^{3}$ \\ Laiane Medeiros Ribeiro ${ }^{4}$ \\ Maria Gorete Lucena de Vasconcelos ${ }^{5}$ \\ Adriana Moraes Leite ${ }^{6}$ \\ Carmen Gracinda Silvan Scochi ${ }^{7}$
}

\begin{abstract}
The relationship between maternal factors and the response of preterm infants to pain and stress experienced during heel puncture while in maternal kangaroo care was investigated. This descriptive study included 42 mothers and their preterm infants cared for in a neonatal unit. Data were collected in the baseline, procedure, and recovery phases. We measured the neonates' facial actions, sleep and wake states, crying, salivary cortisol levels, and heart rate, in addition to the mothers' behavior, salivary cortisol levels, and mental condition. The influence of the maternal explanatory variables on the neonatal response variables were verified through bivariate analysis, ANOVA, and multiple regression. The mothers' behavior and depression and/or anxiety did not affect the neonates' responses to pain and stress, though the mothers' levels of salivary cortisol before the procedure explained the variance in the neonates' levels of salivary cortisol after the procedure $(p=0.036)$. Additionally, the mothers' baseline levels of salivary cortisol along with the neonates' age explained the variance in the neonates' heart rate $(p=0.001)$. The ability of mothers to regulate their own stress contributed to the infants' responses to pain and stress.
\end{abstract}

Descriptors: Neonatal Nursing; Premature Infant; Pain; Mother-Child Relations.

\footnotetext{
${ }^{1}$ Paper extracted from Doctoral Dissertation "A relação entre fatores maternos e a resposta à dor e ao estresse do prematuro em posição canguru", presented to Escola de Enfermagem de Ribeirão Preto, Universidade de São Paulo, WHO Collaborating Centre for Nursing Research Development, Brazil. Supported by FAPESP (2007/05051-1) and CNPq (200113/2008-9).

2 PhD, Adjunct Professor, Faculdade de Enfermagem, Universidade Federal de Goiás, Brasil.

${ }^{3}$ PhD, Assistant Professor, University of British Columbia, School of Nursing, Canada.

${ }^{4}$ Doctoral Student, Escola de Enfermagem de Ribeirão Preto, Universidade de São Paulo, WHO Collaborating Centre for Nursing Research Development, Brazil.

${ }^{5}$ PhD, Adjunct Professor, Departamento de Enfermagem, Universidade Federal de Pernambuco, Brazil.

${ }^{6}$ PhD, Associate Professor, Escola de Enfermagem de Ribeirão Preto, Universidade de São Paulo, WHO Collaborating Centre for Nursing Research Development, Brazil.

7 PhD, Full Professor, Escola de Enfermagem de Ribeirão Preto, Universidade de São Paulo, WHO Collaborating Centre for Nursing Research Development, Brazil.
} 


\section{Fatores maternos influenciam a resposta à dor e ao estresse do neonato em posição canguru}

Investigou-se associação entre fatores maternos e resposta de prematuros submetidos à punção de calcâneo em posição canguru. Trata-se de estudo descritivo envolvendo 42 mães e prematuros de uma unidade neonatal. A coleta ocorreu nos períodos basal, procedimento e recuperação. Mensuraram-se a mímica facial, sono e vigília, choro, cortisol salivar e frequência cardíaca neonatais, além de se mensurar o comportamento, cortisol salivar e estado mental maternos. Analisou-se a influência das variáveis explanatórias maternas nas variáveis de resposta neonatais por análise bivariada, análise de variância e regressão múltipla. A depressão e/ou ansiedade e comportamento materno não influenciaram a resposta do prematuro à dor e estresse. O cortisol salivar pré-punção materno explicou a variância do cortisol salivar pós-punção neonatal $(p=0,036)$; e o cortisol salivar noturno materno, juntamente com a idade pós-natal neonatal, explicaram a variância da frequência cardíaca neonatal $(p=0,001)$. A capacidade das mães em regular seu próprio estresse contribuiu para resposta de dor e estresse do prematuro.

Descritores: Enfermagem Neonatal; Prematuro; Dor; Relações Mãe-Filho.

\section{Los factores maternos regula la respuesta al dolor y al estrés del recién nacido en posición canguro}

Asociación entre los factores maternos y la respuesta de los prematuros sometidos a punción del calcáneo en posición canguro. Estudio descriptivo envolviendo 42 madres y prematuros de una unidad neonatal. La colecta se dio en el período basal, procedimiento y recuperación. Se midieron la mímica facial, sueño y vigilia, llanto, cortisol salival y frecuencia cardíaca neonatal; y el comportamiento, cortisol salival y estado mental materno. Se analizó la influencia de las variables maternas en las variables neonatales por análisis bi-variada, análisis de variancia y regresión múltiple. La depresión, ansiedad y comportamiento materno no influenciaron la respuesta del prematuro al dolor. El cortisol pre-punción materna explico la variancia del cortisol post-punción neonatal $(p=0,036)$; el cortisol nocturno materno, juntamente con la edad post nacimiento neonatal, explicaron la variancia de la frecuencia cardíaca neonatal $(p=0,001)$. La capacidad de las madres en regular su proprio estrés contribuyó para la respuesta del dolor del prematuro.

Descriptores: Enfermería Neonatal; Prematuro; Dolor; Relaciones Madre-Hijo.

\section{Introduction}

We no longer believe that newborns are incapable of feeling pain. Scientific advancements in recent years have contributed to the understanding of anatomical and physiological mechanisms from the time of intrauterine life, as well as contributing to our understanding of the effects of acute pain in preterm and sick newborns. We now acknowledge the existence of continuous pain, in addition to acute and postoperative pain. Scientific advancements also include the development of specific indicators to evaluate pain and determine the effectiveness of neonatal pain treatment ${ }^{(1)}$. Such advancements, however, have not substantially reduced suffering or costs related to pain, which is considered to be a worldwide public health problem that should be treated as a priority for healthcare services $^{(2)}$.

A growing number of children, who are now able to survive with the treatment provided in neonatal units of high technological density, are exposed to a diversity of painful and stressful procedures. An average of 12 painful procedures are performed a day, while the heel puncture is the most frequent $^{(3)}$. The exposure of neonates to pain and stress results in behavioral changes (e.g. facial actions, crying) (4) and immediate biophysiological changes (e.g. increased Heart Rate (HR) and cortisol levels) ${ }^{(5)}$. Repeated procedures 
may result in the frequent activation of stress system, making newborns to spend energy without time to recover ${ }^{(6)}$.

Pain treatment is an essential human right and evidence for its treatment is already available. The kangaroo position stands out among non-pharmacological interventions effective in reducing neonatal pain. It is recommended to alleviate pain from a single heel puncture in full-term and stable preterm newborns ${ }^{(7)}$.

There are various components interacting in the kangaroo position, such as containment, heart beat sound, rhythmic breathing movements, maternal warmth, the prone position ${ }^{(8)}$. Therefore, the mother seems to play an important role in the analgesic mechanism of the kangaroo position, though most mothers addressed in studies evaluating the effectiveness of this intervention were instructed not to touch or talk to the infant(7).

It is believed there are hidden regulating maternal factors that allow mothers to regulate the infant's specific and independent systems, such as behavior, autonomic state, thermoregulation, emotion, and stress ${ }^{(9)}$. Hence, for the mother to comfort the child in a stressful situation, she should first self-regulate, establishing effective interactive communication, acting as an important external factor to regulate the newborn's biobehavior and the development of self-regulating skills, in addition to the establishment of effective bonds throughout the infant's first year of life ${ }^{(10)}$.

Considering the proximity of the mother and child in the kangaroo position, we examine what factors promote or hinder the mother's ability to self-regulate and, consequently, to regulate the newborn during the kangaroo position. We highlight the importance of providing integral and humanized care to newborns ${ }^{(11)}$ with the active participation of the mother and family to prevent acute neonatal pain.

This study's objective was to investigate the association between maternal factors (behavior, depression and/or anxiety, and stress) and the response of newborns to pain and stress when undergoing heel puncture for the neonatal screening test while held in the kangaroo position.

\section{Method}

This descriptive exploratory study was conducted in the Neonatal Intermediary Care Unit (NICU) of a university hospital in the interior of São Paulo, Brazil from July 2008 to January 2010. The study was approved by the hospital's Ethics Research Committee (protocol No. 7999/2007). We estimated a sample of 49 participants based on alpha $=0.05$, the number of predictors $=7$, effect size $=0.35$ and $\beta=0.80$. Newborns with a gestational age $\leq 36$ weeks and six days, Apgar $\geq 7$ at the $5^{\text {th }}$ minute, scheduled for a neonatal screening test, and clinically stable (HR and oxygen saturation within normal levels before data collection) were included in the study. Newborns were not included in the study when they were under assisted ventilatory care, with intraventricular hemorrhaging of grade III or IV or subsequent leukomalacia, were diagnosed with congenital disease of the nervous system, malformation or neurological and renal damage, using corticosteroids or drugs that interfere in the response to nociception, or those with a twin sibling included in the study. With regard to mothers, those with the cognitive ability to understand the instruments were included in the study, while those with a current diagnosis of psychiatric disease other than anxiety and depression or those using corticosteroids or drugs that interfere in nociception or with renal disease were excluded.

Of the 217 recruited mother-child dyads, 148 $(68.2 \%)$ did not participate in the study due to various reasons, such as being transferred to another unit and difficult access to mothers. Data were collected from 69 mother-child dyads, though 27 (39.1\%) were excluded from the analysis either due to the mother's unavailability to attend the interview, insufficient volume of saliva, or failure during filming, among other reasons. Therefore, 42 mother-child dyads composed the final sample and a post-hoc $\beta=0.77$ was obtained.

The studied neonatal variables included facial actions, sleep and wake states, crying, HR and salivary cortisol levels while the maternal variables included behavior, salivary cortisol levels, and depression and/or anxiety. The period in which each variable was measured is presented in Figure 1.

The mothers' and infants' behavioral data were filmed by two digital SONY Handycam model DVD92 camcorders. Two trained individuals coded, second-bysecond, the neonatal behavioral variables (facial actions, sleep and wake states) in addition to the maternal variable (behavior), using digital images through the Magix Movie Editor 15 Pro Plus. Three facial actions (eyebrow bulge, squeezed eyes, and naso-labial furrow) of newborns and five sleep-wake states (deep sleep, active sleep, quiet wake, active wake, and crying)(13) were coded through the Neonatal Facial Coding System (NFCS $^{(12)}$. The 23 categories of mothers' behavior were coded through the Maternal Mood and Behavior during her Infant Pain Coding System (MMBIPCS) and later grouped into 'typical' and 'typically depressed'(14). Inter-rater reliability was computed through the Kappa coefficient with the Generalized Sequential Querier (GSEQ), version 5.0, and the following was obtained: $\mathrm{k}=90 \%, \mathrm{k}=84 \%$ and $\mathrm{k}=84 \%$, respectively. 
Neonatal HR was obtained using three Red Dot 2258-3 electrodes, installed on all the newborns, and connected to the Polar RS200 heart rate monitor. A psychologist assessed the mothers' anxiety and depression levels using the Beck Depression Inventory (BDI) and the Beck Anxiety Inventory (BAI)(15). The general introductory part of the Structured Clinical Interview DSM-IV-SCID-CV(16) was used to describe the psychiatric history of mothers. Based on the scores obtained in the BDI and BAI and the duration of anxiety in mothers during the procedure, newborns were divided into two groups: 'exposed' (BDI $\geq 18, \mathrm{BAI} \geq 20$ and MMBIPCS>30s) $(n=17)$ and 'non-exposed' (BDI<18, $B A I<20$ and MMBIPCS $\leq 30 s) \quad(n=25)$ to maternal depression and/or anxiety. Nursing assistants, nurses and the psychologist, trained prior to data collection, collaborated in the study.

After the mothers and/or legal guardians signed free and informed consent forms, the mothers received identified Salivettes ${ }^{\circledR}$ tubes with written instructions to collect two samples of saliva, one at the night prior to the exam, and the other on the morning of the exam day. Another saliva sample was collected from both the newborn and the mother prior to the neonatal screening test while the infant was in a supine position, either in the incubator or crib, and the mother was seated close to her child. For the next 10 minutes, the newborn's HR was monitored and his/her face was filmed while in the incubator or crib (baseline phase). Afterward, the newborn was positioned in maternal kangaroo care for 15 minutes $^{(17)}$. A nurse collected blood for the neonatal screening test in accordance with the unit's protocol using a Unistik ${ }^{\circledR}$ lancet (procedure phase) while the mother's behavior and interaction with the newborn were also filmed. After the exam, the newborn was kept in the kangaroo position for another ten minutes (recovery phase). The video recording and cardiac monitoring ceased and the newborn was transferred to the incubator or crib where s/he remained without any manipulation for another ten minutes when an additional sample of saliva after the procedure was collected from both the mother and child. A psychologist applied the BDI, BAI and the SCID-CV within one to seven days after the procedure (Figure 1 ).

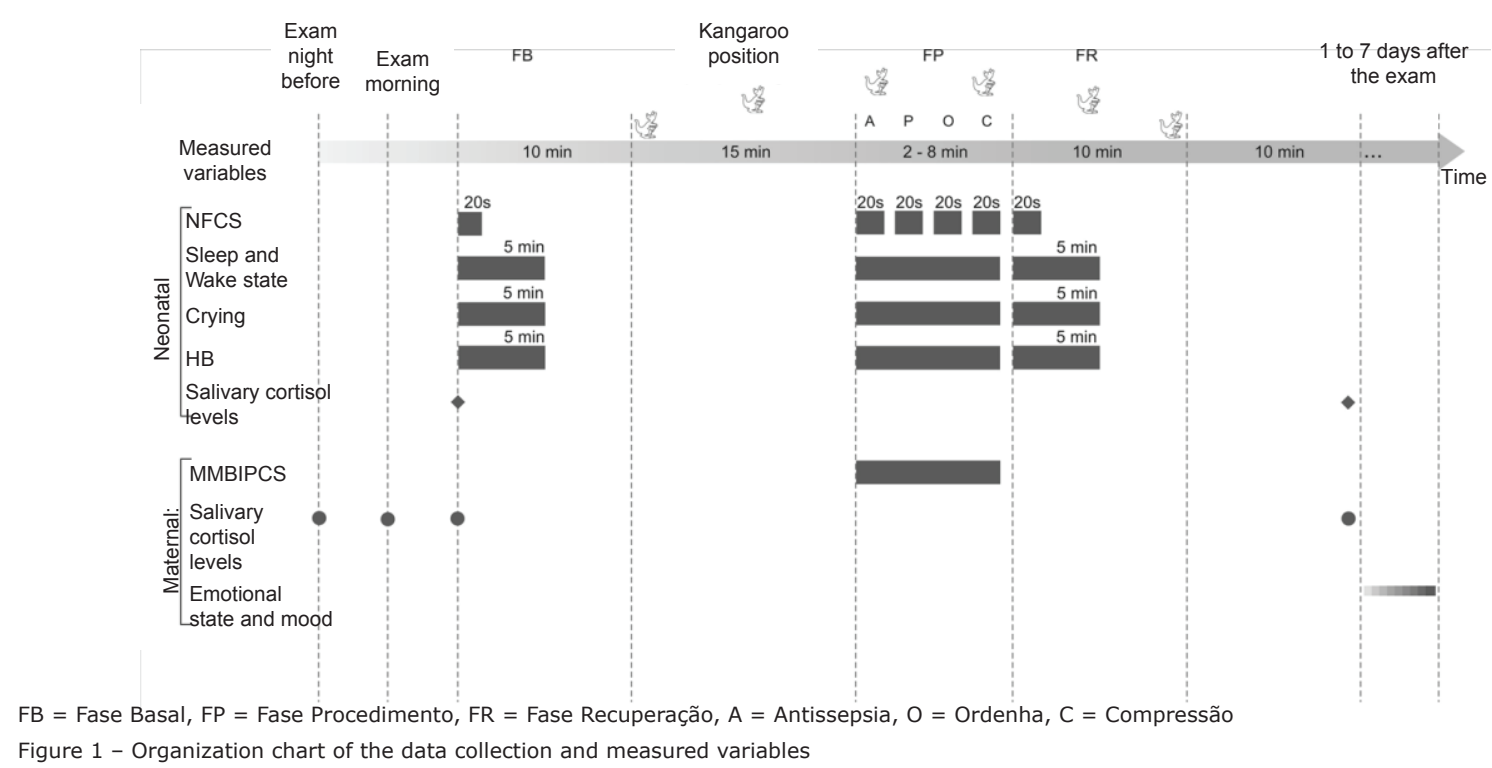

Figure 1 - Organization chart of the data collection and measured variables

Colored envelops marked the beginning of each phase of data collection during filming. The infants' and mothers' medical records were searched so that their clinical and demographic variables were collected. The number of painful procedures performed in the 24 hours prior to the screening test was obtained through records in the infants' medical files and exams requests.

Data were stored in the Statistical Package for the Social Sciences version 17.0 through double entry. The duration (seconds) and percentage of time [(duration of behavior/duration of phase) $x$ 100] of neonatal and maternal behaviors were computed through GSEQ and the mean duration calculated for the NFCS, neonatal $\mathrm{HR}$ and maternal and neonatal salivary cortisol levels in each phase of the data collection (baseline, procedure, recovery).

The relationship between the newborns' response variables (NFCS score, percentage of time of crying, HR and salivary cortisol levels) and the mothers' explanatory variables (percentage of time of behavior and salivary cortisol levels) were initially examined for each phase through bivariate analysis, with 
$\alpha=0.20$. Repeated Measures Analysis of Variance was performed for the explanatory variables, the mothers' depression and/or anxiety. A multiple regression analysis was performed for each neonatal variable (NFCS score, percentage of time of cry, HR, and levels of salivary cortisol after the procedure) to verify which maternal explanatory variables influenced the neonatal response variables during the procedure; the alpha was fixed at 0.05 .

\section{Results}

The neonatal screening test lasted an average of $4 \pm 1.6$ minutes ( 2.5 to 8.7 minutes); 33 (78.6\%) infants were punctured only once during the blood collection. The clinical and demographic characteristics of newborns and their mothers are presented in Table 1.

Table 1 - Clinical and demographic characteristics of newborns and mothers

\begin{tabular}{|c|c|c|}
\hline Characteristics & $f(\%)$ & Average \pm \\
\hline \multicolumn{3}{|l|}{ Newborns } \\
\hline Gestational age (weeks) & & $32.5 \pm 1.8$ \\
\hline Birth weight (g) & & $1795.6 \pm 618.4$ \\
\hline Apgar at the $5^{\text {th }}$ minute & & $9.5 \pm 0.7$ \\
\hline Gender (Male) & $30(71.4)$ & \\
\hline C-section & $29(69.0)$ & \\
\hline Twins & $8(19.0)$ & \\
\hline \multicolumn{3}{|l|}{ Mothers } \\
\hline Age & & $24.5 \pm 5.9$ \\
\hline Number of people living in the house & & $4.3 \pm 1.7$ \\
\hline Primigravida & $20(47.6)$ & \\
\hline \multicolumn{3}{|l|}{ Marital status } \\
\hline Cohabitating & $17(40.5)$ & \\
\hline Married & $13(30.9)$ & \\
\hline Single & $10(23.8)$ & \\
\hline Divorced & $2(4.8)$ & \\
\hline \multicolumn{3}{|l|}{ Education } \\
\hline Primary school & $21(50.0)$ & \\
\hline Secondary school & $17(40.5)$ & \\
\hline College & $4(9.5)$ & \\
\hline \multicolumn{3}{|l|}{ Occupation } \\
\hline Employed & $29(69.0)$ & \\
\hline Unemployed & $13(31.0)$ & \\
\hline
\end{tabular}

$\overline{\mathrm{X}}=$ average $; \pm=$ standard deviation; $\mathrm{f}=$ absolute frequency $\%$ \%=percentage.

Most mothers (61.9\%) did not present depression or only mild depression (14.9\%). Ten (23.8\%) mothers presented moderate depression and none presented severe depression. Similarly, most mothers did not present anxiety $(52.4 \%)$ or it was mild $(26.2 \%)$. Nine $(21.4 \%)$ mothers presented moderate $(19.0 \%)$ or severe $(2.4 \%)$ anxiety. Eleven (26.2\%) out of the total number of mothers presented depression and anxiety simultaneously. The average scores obtained by the mothers on the BDI and BDA were $11.4 \pm 8.2$ and $12.0 \pm 9.9$, respectively. The first time most mothers $(71.4 \%)$ used the kangaroo position was during this study.

Associations were found between the NFCS scores obtained during the procedure phase and: the mothers' levels of salivary cortisol collected prior to the puncture $(r=0.32 ; p=0.040)$; the percentage of time newborns cried during the procedure and the levels of mothers' salivary cortisol collected prior to the procedure $(r=-0.32 ; p=0.047)$; the neonatal HR measured during the procedure and the mothers' salivary cortisol collected the night before $(r=-0.49$; $p=0.002)$, collected before puncture $(r=-0.34 ; p=0.025)$, and after the puncture $(r=-0.51 ; p=0.001)$; neonatal $H R$ measured during recovery and the mothers' levels of salivary cortisol collected the night before $(r=-0.45 ; p=0.004)$, before the puncture $(r=-0.41 ; p=0.007)$, and after the puncture $(r=-0.50 ; p=0.001)$; the newborns' levels of salivary cortisol collected before the puncture and the mothers' salivary cortisol collected the night before $(r=0.39 ; p=0.016)$; and also the levels of salivary cortisol of newborns and mothers collected after the puncture $(r=0.34 ; p=0.027)$. Neither the mothers' anxiety and depression nor their behavior influenced the infants' facial actions [Wilk's Lambda $=0.976$; $F(2.39)=0.480 ; p=0.623$ ], crying [Wilk's Lambda $=0.990$; $F(2.39)=0.201 ; \quad p=0.818], \quad H R \quad[F(1.88 ; 75.07)=1.715$; $\mathrm{p}=0.189]$ or the newborns' levels of salivary cortisol $[F(1.39)=0.367 ; p=0.548]$.

Before proceeding to the regression analysis, the following potential confounding variables were tested in relation to the neonatal response variables (NFCS score, percentage of time of crying, average HR, and average level of salivary cortisol after the puncture was performed) using Person's coefficient of correlation: the neonatal variables (gender, GA, age, number of pain events in the $24 \mathrm{hrs}$ prior to the procedure, and average percentage of times of the sleep and wake states during the baseline phase); the maternal variables (use of corticosteroids during pregnancy and previous experience with the kangaroo method); and variables related to the neonatal screening test (number of punctures and duration of the procedure). We verified the relationship among the confounding variables to test the multicollinearity among variables. Only some neonatal and maternal variables presented a statistically significant relationship $(p<0.05)$ among them or with the neonatal dependent variables (Table 2 ).

Multiple regression analysis was not performed for the variables 'facial actions' and 'crying' because these did not meet the homoscedasticity assumption. 
Table 2 - Person's linear correlation matrix $(r)$ and values of $p$ probabilities among the neonatal response variables during the procedure and neonatal and maternal confounding variables.

\begin{tabular}{|c|c|c|c|c|c|c|c|c|c|c|}
\hline & GA & Age & Gender & Pain & DS & SA & QW & AW & CR & MK \\
\hline GA & & $-0.51^{\dagger}$ & n.s & $0.34^{\star}$ & n.s & n.s & n.s & n.s & n.s & $0.42^{*}$ \\
\hline Age & $-0.51^{\dagger}$ & & n.s & $-0.52^{\dagger}$ & n.s & n.s & n.s & n.s & n.s & $-0.53^{\dagger}$ \\
\hline Gender & n.s & n.s & & n.s & n.s & n.s & n.s & n.s & n.s & n.s \\
\hline Pain & $0.34^{*}$ & $-0.52^{\dagger}$ & n.s & & n.s & n.s & n.s & n.s & n.s & n.s \\
\hline DS & n.s & n.s & n.s & n.s & & n.s & $-0.54^{\dagger}$ & $-0.47^{*}$ & n.s & n.s \\
\hline AS & n.s & n.s & n.s & n.s & n.s & & $-0.49^{\dagger}$ & $-0.51^{\dagger}$ & $-0.40^{*}$ & n.s \\
\hline QW & n.s & n.s & n.s & n.s & $-0.54^{\dagger}$ & $-0.49^{\dagger}$ & & n.s & n.s & n.s \\
\hline AW & n.s & n.s & n.s & n.s & $-0.47^{*}$ & $-0.51^{\dagger}$ & n.s & & n.s & n.s \\
\hline CR & n.s & n.s & n.s & n.s & n.s & $-0.40^{*}$ & n.s & n.s & & n.s \\
\hline MK & $0.42^{*}$ & $-0.53^{\dagger}$ & n.s & n.s & n.s & n.s & n.s & n.s & n.s & \\
\hline NFCS & $0.37^{*}$ & n.s & n.s & n.s & n.s & n.s & n.s & n.s & n.s & $0.37^{*}$ \\
\hline Crying & n.s & n.s & n.s & $-0.36^{\dagger}$ & n.s & $-0.32^{*}$ & n.s & n.s & n.s & $-0.36^{*}$ \\
\hline $\mathrm{HR}$ & n.s & $0.47^{*}$ & n.s & n.s & n.s & $-0.37^{*}$ & n.s & n.s & n.s & $-0.33^{*}$ \\
\hline Cortisol & n.s & $-0.34^{*}$ & n.s & n.s & n.s & n.s & n.s & n.s & n.s & $0.38^{*}$ \\
\hline
\end{tabular}

$\mathrm{GA}=$ gestational Age; Pain=number of pain events in the $24 \mathrm{hrs}$ prior to the procedure; $\mathrm{DS}=$ average percentage of time in baseline deep sleep; $\mathrm{AS}=$ average time in baseline active sleep; $\mathrm{QW}=$ average percentage of time in baseline quiet wake state; $A W=$ average percentage of time in baseline active wake state; $\mathrm{CR}=$ average percentage of time in baseline crying; $\mathrm{MK}=$ maternal experience with kangaroo method before the procedure; NFCS= score obtained on the pain scale; Cry= average percentage of time crying; $\mathrm{HR}=$ average neonatal $\mathrm{HR}$. Cortisol=levels of salivary cortisol before the puncture. $* 0.01<\mathrm{p}<0.05 ;{ }^{+} \mathrm{p}<0.01$; n.s. $=$ not statistically significant.

The explanatory model of the neonatal HR during the procedure is presented in Table 3 . The mothers' levels of salivary cortisol and the newborns' age contributed significantly to the model; the mothers' levels of salivary cortisol collected the night before the procedure had a greater contribution. These two variables explained $28.2 \%$ of the variance of newborns' HR during the procedure [adjusted coefficient $\mathrm{R}^{2}=0.282 ; F(2.35)=8.219 ; p=0.001$ ].
The model proposed to explain the variation in the salivary cortisol levels of newborns before the procedure is presented in Table 4. The mothers' levels of salivary cortisol before the procedure significantly contributed to the model, explaining $9.2 \%$ of the variance in the newborns' salivary cortisol levels before the procedure [adjusted coefficient $\mathrm{R}^{2}=0.092$; $F(1.36)=4.764 ; p=0.036]$.

Table 3 - Linear regression model for neonatal HR during procedure

\begin{tabular}{|c|c|c|c|}
\hline Independent variables & $\beta$ & $\mathbf{t}$ & $\mathbf{p}$ \\
\hline Mothers' salivary cortisol from the night before the procedure & -0.35 & -2.243 & $0.031^{*}$ \\
\hline Newborns' age & 0.32 & 2.088 & $0.044^{*}$ \\
\hline Newborn's percentage of time in active sleep (baseline) & -0.21 & -1.461 & 0.153 \\
\hline Newborn's exposure to the mother's depression/anxiety & -0.15 & -1.074 & 0.290 \\
\hline Mother's salivary cortisol levels right before the procedure & -0.10 & -0.601 & 0.552 \\
\hline Mother's experience with kangaroo prior to the procedure & -0.03 & -0.168 & 0.868 \\
\hline
\end{tabular}

$\beta=$ standardized weight; $t=$ statistics $t ; * p<0.05$

Table 4 - Linear regression model for the newborns' levels of salivary cortisol after the procedure

\begin{tabular}{|c|c|c|c|}
\hline Independent variables & $\beta$ & $\mathbf{t}$ & $p$ \\
\hline Mothers' salivary cortisol levels before the procedure & 0,34 & 2,183 & $0,036^{*}$ \\
\hline Mothers' salivary cortisol levels from the night before & 0,22 & 1,355 & 0,184 \\
\hline Mothers' experience with kangaroo prior to the procedure & 0,24 & 1,492 & 0,145 \\
\hline Newborns' age & $-0,21$ & $-1,081$ & 0,287 \\
\hline Mothers' salivary cortisol levels after the procedure & 0,08 & 0,437 & 0,665 \\
\hline
\end{tabular}

$\beta=$ standardized weight; $\mathrm{t}=$ statistics $\mathrm{t} ; * \mathrm{p}<0.05$ 


\section{Discussion}

This paper presented an investigation of maternal factors related to newborns' responses to pain and stress when exposed to the neonatal screening test while in the kangaroo position. Various significant associations were found, suggesting the existence of a co-regulation between mother and child in the context of neonatal pain and stress while the infant is held in the kangaroo position. Maternal salivary cortisol levels, which are an indicator of stress, were associated with various neonatal variables (NFCS score, duration of crying, HR, and salivary cortisol levels), though no association was found between the mothers' salivary cortisol levels and their own behavior (typical and typically depressed) or depression and/or anxiety. The relationship between the mothers' salivary cortisol levels and neonatal variables is still seldom studied in the context of neonatal pain. No other study has examined this relationship when the infant experiences such a painful event while held in the kangaroo position.

The mothers' levels of salivary cortisol before the procedure explained the variance in the newborns' levels of salivary cortisol after the procedure. Such findings are similar to those of another study addressing the relationship between plasma levels of cortisol and maternal psychosocial stress with the behavioral and physiological responses of full-term newborns to calcaneal heel puncture. The study reports that high levels of plasma cortisol observed in mothers during pregnancy explained high levels of salivary cortisol observed in their infants after the procedure and during recovery ${ }^{(18)}$. This study's results add to such evidence beyond the prenatal period to the population of preterm newborns.

There was also a positive association between the mothers' salivary cortisol levels and the newborns' pain scores (NFCS). This is the first time this relationship is reported in the literature. Such a relationship, however, requires further investigation through statistical analysis that would allow adjusting for potential confounding variables. A more refined analysis of this variable was not possible in this study due to restrictions imposed by the statistical assumption of homoscedasticity.

The mothers' levels of salivary cortisol from the night before, along with the newborns' GA, were predictors of neonatal HR. The relationship between the autonomic nervous system and the hypothalamicpituitary-adrenal (HPA) axis is very complex. The inverse relationship between the cortisol level and HR variability may be explained by a system of negative feedback in which appropriate HPA axis regulation is influenced, in part, by the modulation of the autonomic nervous system(19). Since the kangaroo position involves very close contact between mother and child, the inverse relationship between the newborns' HR and the mothers' salivary cortisol levels suggests there is mediation of the kangaroo position in relation to the newborns' autonomic nervous system and HPA axis. The close contact also encourages the self-regulation of maternal stress, which contributes to the effectiveness of the kangaroo position in alleviating neonatal pain and stress. Even though these assumptions cannot be appropriately confirmed due to the lack of a control group not using the kangaroo position, we observed that the mothers' stress contributed to their newborns' responses to pain and stress caused by the neonatal screening test.

In contrast with the mothers' salivary cortisol levels, the mothers' behavior and depression and/or anxiety did not affect the newborns' responses to pain and stress. Six studies, addressing only full-term infants in the context of vaccination, also evaluated maternal behavior during a painful event experienced by newborns ${ }^{(20-24)}$. Even though a positive association was found between the maternal behavior and the responses of infants to pain, such an association was weak in most cases. Additionally, only two studies used a validated scale to measure neonatal pain, while the maternal behavior was evaluated differently in the different the studies. Both the infants' and the mothers' behavior was coded in intervals of time (e.g. at each five second point) and not second-by-second as we did in this study.

Depression and/or anxiety of mothers has been seldom investigated in the context of neonatal pain. Among the factors that may have contributed to the fact that no positive association was found between the mothers' depression and/or anxiety and the responses of their newborns to pain is the reduced number of mothers with depression and/or anxiety in the sample, the exclusive use of self-reporting instruments, and evaluation in the post delivery period. Depression and/ or anxiety experienced during pregnancy may expose newborns to a greater risk of presenting an altered response to pain and stress. Future studies should assess mothers both in the prenatal and post-natal periods, as well as use both self-reporting scales and observation.

Finally, maternal kangaroo care may have softened the negative effect of depression and anxiety in the response and regulation of newborns. The prevalence of post delivery depression in mothers using the mother-child kangaroo method during the hospitalization of infants in a neonatal unit decreased, from $37.3 \%$ at admission, to $16.9 \%$ at discharge $(p<0.001)^{(25)}$. Nevertheless, a causal 
relationship between the kangaroo position and a lack of negative effects in the exposure of newborns to their mothers' depression and/or anxiety was not established in this study due to the non-existence of a control group (lacking kangaroo position).

\section{Conclusion}

Maternal stress, measured through the mothers' levels of salivary cortisol collected during the post delivery period, influenced the response of newborns to pain and stress when subject to the neonatal screening test in the kangaroo position. The newborns' HR variations were explained by the mothers' salivary cortisol levels taken the night before and newborns' age; with a greater contribution of the mothers' cortisol levels to the model. The mothers' cortisol levels observed before the procedure explained the newborns' cortisol levels in response to the painful exam. This study's limitations are the relatively small number of mothers in the group with depression and/or anxiety in addition to the impossibility to establish a causal relationship among variables due to the study's cross-sectional nature. We expect this study to contribute to the acknowledgement that mothers play an important role in the regulation of stress and acute pain for preterm infants while being held in the kangaroo position. This study's findings can also support the development of protocols to implement the kangaroo position for the management of neonatal acute pain, favoring the interaction between mother and newborn and the establishment of more integrated and humanized neonatal care with the active participation of mothers.

\section{Acknowledgement}

We acknowledge Professor Claudia Benedita dos Santos for the statistical assistance, Professor Sonir R. R. Antonini for the assistance with analysis of salivary cortisol, the laboratory technician José Roberto for the trials with salivary cortisol, the nurses Andreara, Mariana, Laiane and Fernanda for their help with the coding of behavioral images, the research assistants Aline, Carol, Joselaine, Leticia, Mayra and Mariana for their help in data collection, the nurse Thaiomara for the recruitment of subjects and the psychologists Leticia and Laura for the assessment of the emotional state and mood of the mothers.

\section{References}

1. Stevens BJ, Anand K, McGrath PJ. An overview of pain in neonates and infants. In: Stevens BJ, Anand KJS, McGrath PJ. Pain in neonates and infants. 4th ed. Philadelphia (PA): Elsevier; 2007. p. 1-9.
2. Finley GA, Franck LS, Grunau RE, von Baeyer CL. Why children's pain matter? Pain Clin Updates. 2005;13(4):1-6.

3. Carbajal R, Rousset A, Danan C, Coquery S, Nolent $P$, Ducrocq $S$ et al. Epidemiology and treatment of painful procedures in neonates in intensive care units. JAMA. 2008;300(1):60-70.

4. Grunau RE, Holsti L, Haley DW, Oberlander T, Weinberg J, Solimano A, et al. Neonatal procedural pain exposure predicts lower cortisol and behavioral reactivity in preterm infants in the NICU. Pain. 2005;113(3):293-300.

5. Grunau RE, Tu MT, Whitfield MF, Oberlander TF, Weinberg J, Yu W et al. Cortisol, behavior, and heart rate reactivity to immunization pain at 4 months corrected age in infants born very preterm. Clin J Pain. 2010; 26(8):698-704.

6. Gunnar M, Quevedo K. The neurobiology of stress and development. Annu Rev Psychol. 2007;58:145-73.

7. Warnock F, Castral TC, Brant R, Sekilian M, Leite AM, Owens Sde $L$ et al. Brief report: Maternal kangaroo care for neonatal pain relief: a systematic narrative review. J Pediatr Psychol. 2010;35(9):975-84.

8. Ludington-Hoe SM, Swinth JY. Developmental aspects of kangaroo care. JOGNN. 1996;25(8):691-703.

9. Hofer MA. Hidden regulators in attachment, separation, and loss. Monogr Soc Res Child Dev. 1994;59(2-3):192-207.

10. Schore AN. Back to basics: attachment, affect regulation, and the developing right brain: linking developmental neuroscience to pediatrics. Pediatr Rev. 2005;26(6):204-17.

11. Rolim KMC, Cardoso MVLML. Discourse and practice of care to newborns at risk: Reflecting about humanized care. Rev. Latino-Am. Enfermagem. 2006;14(1):85-92.

12. Grunau RV, Craig KD. Pain expression in neonates: Facial action and cry. Pain. 1987;28(3):395-410.

13. Prechtl $\mathrm{H}$. The behavioural states of the newborn infant (a review). Brain Res. 1974;76(2):185-212.

14. Warnock F, Bakeman R, Shearer K, Misri S, Oberlander T. Caregiving behavior and interactions of prenatally depressed mothers (antidepressant-treated and nonantidepressant-treated) during newborn acute pain. Infant Ment Health J. 2009;30(4):384-406.

15. Cunha J. Manual da versão em português das Escalas Beck. São Paulo (SP): Casa do Psicólogo; 2001.

16. Del-Ben CM, Rodrigues CR, Zuardi AW. Reliability of the Portuguese version of the structured clinical interview for DSM-III-R (SCID) in a Brazilian sample of psychiatric outpatients. Braz J Med Biol Res. 1996;29(12):1675-82.

17. Castral TC, Warnock F, Leite AM, Haas VJ, Scochi CG. The effects of skin-to-skin contact during acute pain in preterm newborns. Eur J Pain. 2008;12(4):464-71. 
18. Davis EP, Sandman CA. The timing of prenatal exposure to maternal cortisol and psychosocial stress is associated with human infant cognitive development. Child Dev. 2010;81(1):131-48.

19. Thayer JF, Hall M, Sollers III JJ, Fischer JE. Alcohol use, urinary cortisol, and heart rate variability in apparently healthy men: Evidence for impaired inhibitory control of the HPA axis in heavy drinkers. Int J Psychophysiol. 2006;59(3):244-50.

20. Jahromi LB, Putnam SP, Stifter CA. Maternal regulation of infant reactivity from 2 to 6 months. Dev Psychol. 2004;40(4):477-87.

21. Axia G, Bonichini S. Are Babies Sensitive to the Context of Acute Pain Episodes? Infant Distress and Maternal Soothing During Immunization Routines at 3 and 5 Months of Age? Infant Child Dev. 2005;14:51-62.

22. Braarud HC, Stormark KM. Maternal soothing and infant stress responses: soothing, crying and adrenocortical activity during inoculation. Infant Behav Dev. 2006;29(1):70-9.

23. Piira T, Champion GD, Bustos T, Donnelly $N$, Lui $\mathrm{K}$. Factors associated with infant pain response following an immunization injection. Early Human Dev. 2007;83(5):319-26.

24. Din L, Pillai Riddell R, Gordner S. Brief report: maternal emotional availability and infant pain-related distress. J Pediatr Psychol. 2009;34(7):722-6.

25. De Alencar AE, Arraes LC, De Albuquerque EC, Alves JG. Effect of kangaroo mother care on postpartum depression. J Trop Pediatr. 2009;55(1):36-8. 